\title{
VASCULARISED RIB GRAFTS FOR STABILISATION OF KYPHOSIS
}

\author{
DAVID S. BRADFORD, YOUSSEF H. DAHER
}

From the Twin Cities Scoliosis Center, Minneapolis

\begin{abstract}
The results of vascularised rib graft transfers are analysed in 25 patients followed up for more than two years (average 34 months). Radiographs showed early and rapid incorporation of the grafts in 4 to 16 weeks (average 8.5 weeks); external immobilisation averaged 11 weeks (range 5 to 24 weeks). The technique seems a useful alternative to allografts or homografts employing an avascular rib or fibula since it promotes rapid healing without needing microsurgical techniques.
\end{abstract}

Microvascular surgical techniques as a method of bridging bone defects have become increasingly popular (Weiland. Moore and Daniel 1983), and it is thus surprising that they have not been applied more frequently to spinal deformities. In the management of structural kyphosis and or vertebral body resection for tumour, trauma. or infection. strut grafting with homografts or allografts is a standard procedure (Hodgson and Stock 1960: Hodgson 1965: Stener 1972; Bradford et al. 1977; Hall and Poitras 1977: Streitz, Brown and Bonnett 1977; Moe 't al. 1978; Bradford et al. 1982; McBride and Bradford 1983). It is well documented, however, that such grafts may take up to two years to incorporate and may fracture during the healing phase (Streitz et al. 1977; Bradford 't al. 1982). A vascularised fibular graft could avoid these difficulties by providing immediate stability and rapid healing (Johnson and Robinson 1968), but a vascularised rib graft might be preferable since this type of graft is available more readily and small-vessel anastomosis is unnecessary.

Rose. Owen, and Sanderson (1975) proposed, for stabilisation of kyphosis, a technique of transposing the rib with its blood supply intact, and in an independent report Bradford presented a similar technique (Bradford 1980). To date our patients who have had this procedure have not been reported. and it is our purpose to review this technique and to discuss its possible role in spinal reconstructive surgery.

\section{PATIENTS AND METHODS}

From June 1978 to July 1982, the first author treated 27 patients using vascularised rib grafts; two patients were lost to follow-up. leaving 25 for review (Fig. 1). There

D. S. Bradford. MD. Professor of Orthopaedic Surgery Y. H. Daher, MD. Research Fellow

Department of Orthopaedic Surgery. University of Minnesota, Box 189 Mayo, 420 Delaware Street SE. Minneapolis, Minnesota 55455. USA.

Requests for reprints should be sent to Dr D. S. Bradford.

1 1986 British Editorial Society of Bone and Joint Surgery $0301-620 \times 863072 \$ 2.00$ were 12 women and 13 men whose ages ranged from 16 to 66 years (average 33 years). The cause of the kyphosis was trauma in 20, infection in three (osteomyelitis in two. tuberculosis in one), post-laminectomy in one, and a myelomeningocele in one.

Radiographs were evaluated pre-operatively, postoperatively, and at follow-up and the angles of kyphosis and scoliosis were measured using the Cobb technique. Additional investigations included: lateral planograms of the injured segment: myelography performed in all patients with persistent or increasing neurological deficit: and a CT scan both pre-operatively and postoperatively to evaluate the spinal canal and the quality of incorporation of the rib strut graft. In two patients an aortogram was done; in one the quality was poor and vascular patency difficult to discern. In the second the aortogram

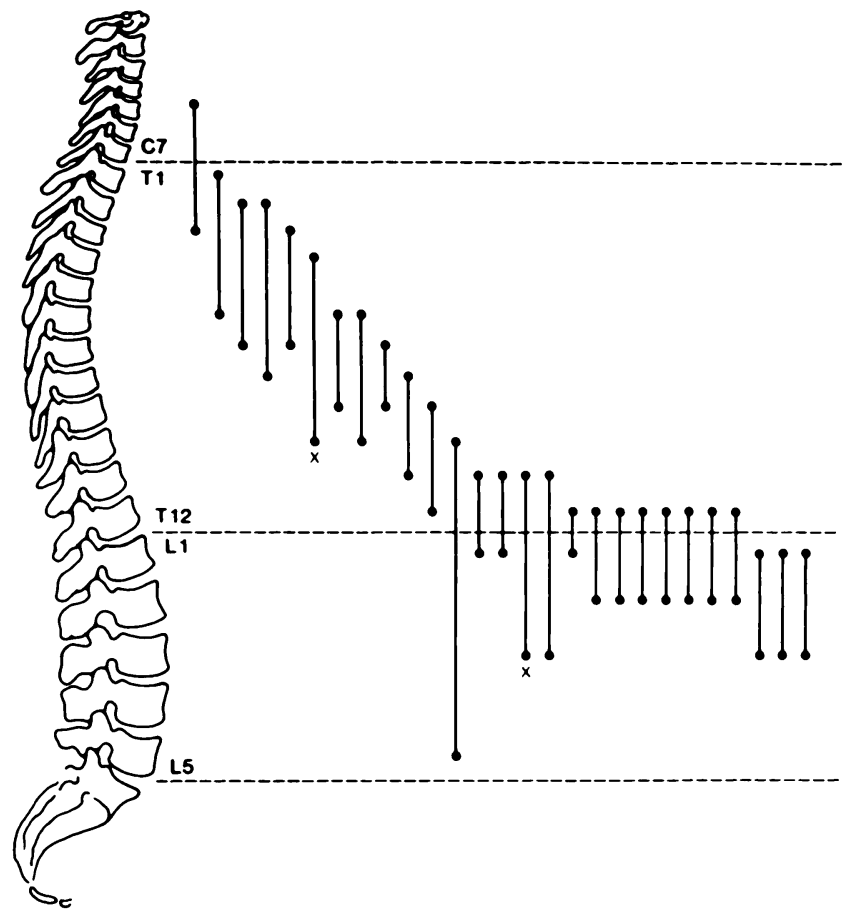

Fig. 1

Levels of fusion using a vascularised rib strut graft in 27 patients: two were lost to follow-up $(x)$ 


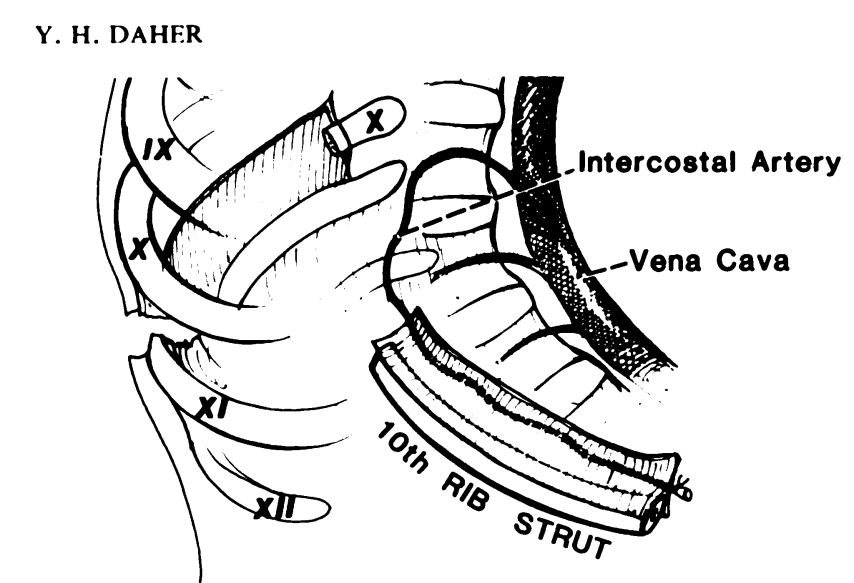

showed that the intercostal vessel to the rib graft was patent and that the graft was intact with apparent bony hypertrophy (Bradford 1980). The rib chosen was noted as well as the number of vertebrae within the fusion. The distance of the strut graft from the apical vertebra was measured on the lateral radiograph or, if there was more than 25 of scoliosis, on the oblique film.

Indications for operation. Sixteen of the 25 patients had had previous non-operative treatment for kyphosis: four were treated by bed rest, seven by bed rest and a brace or cast, two by a brace, two by a cast, and one by a halo cast. The remaining nine patients had had previous operative treatment: a laminectomy in four, laminectomy plus arthrodesis in two, and arthrodesis alone in three patients. In all patients the indication for operation was either progression of the kyphosis or pain or both. Thirteen patients were treated by anterior spinal decompression. six patients by a vertebral body replacement with a femoral neck allograft associated with a vascularised rib graft, and one patient by the insertion of a newly developed anterior implant. Five had an additional posterior spinal fusion with instrumentation. The vascularised rib grafts ranged in length from 5 to $16 \mathrm{~cm}$, the average length being $9 \mathrm{~cm}$.

In 17 patients the grafts were inlaid into slots within the vertebral bodies; in eight patients the grafts lay anterior to the vertebral bodies at the apex of the kyphos and were classified as strut grafts. The distance from the apical vertebra to the strut graft (measured on the lateral or oblique radiographs) ranged from 10 to $45 \mathrm{~mm}$ (average $27 \mathrm{~mm}$ ). The number of fused vertebrae averaged four (range two to eight); posterior arthrodesis was also done in five patients with compression Harrington rods in three. compression and distraction rods in one, and a distraction rod with segmental wire fixation in one. Blood loss ranged from 450 to $5000 \mathrm{ml}$ (average $1978 \mathrm{ml}$ ). Postoperative immobilisation consisted of a Risser cast in six, a body jacket or brace in 11, a cast followed by a brace in five, and a halo cast in one; two patients had no external immobilisation.

Operative technique. A thoracotomy is planned so that the blood supply of the rib to be removed will not be compromised by the bony procedure. If stabilisation and fusion in situ is planned for a kyphosis extending proximal to T5, a rib one or two segments below the distal vertebra of the kyphosis is removed; the distal end of the rib graft is rotated to reach the proximal vertebra whose fusion is planned. If the kyphosis does not extend proximal to T5, a rib one or two above the distal vertebra of the kyphosis is removed, rotating its distal portion to reach the distal vertebral body to be fused. If, on the other hand, an anterior cord decompression is planned, it is preferable to remove the rib corresponding to the level of the apex of the kyphosis in order to facilitate exposure for the decompression. For arthrodesis of the thoracolumbar or lumbar spine, removal of the tenth rib (maintaining its vascularised pedicle) is sufficient.

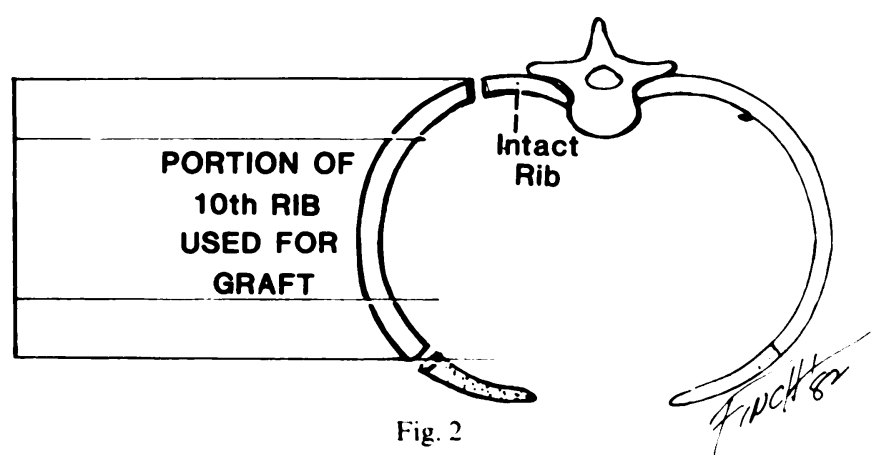

The tenth rib is mobilised on its vascular pedicle and used as the graft.

The skin is prepared in a routine fashion and the skin incision is made along the rib to be mobilised. The cautery knife is used to cut the intercostal muscle at the superior border of the rib; it can also be used on the inferior border, but a cuff of intercostal muscle of approximately 4 to $5 \mathrm{~mm}$ should be left attached to the rib to avoid damaging the intercostal vessels. The rib is cut distally at its sternocostal junction and the distal vessels are ligated with clips. Detachment then proceeds proximally. Chest retractors are placed in position and identification of the intercostal vessel on the inside of the chest facilitates more proximal dissection. The rib is divided at its posterior angle after careful subperiosteal dissection and the intercostal vessels are mobilised over the anterior longitudinal ligament facilitating a more mobile vascular pedicle (Fig. 2). The rib may be shortened from its proximal or distal portion depending upon the length needed for fusion. The rib on its vascularised pedicle is then placed loosely into the chest and exposure to the spine increased if needed. Should anterior decompression be necessary, great care must be taken to avoid damaging the intercostal vessels during this procedure. If in situ arthrodesis is indicated, the proximal and distal vertebral bodies are exposed and the disc excised. A triangle is cut into the bodies, the graft is trimmed to fit snugly into the slot and is then wedged into the vertebrae above and below. Circulation of the rib may be checked by making an incision 1 to $2 \mathrm{~cm}$ long in the periosteum over the rib: brisk bleeding confirms an intact blood supply.

With a thoracolumbar kyphosis, the same technique may be used through a thoraco-abdominal approach 
mobilising the ninth or tenth rib in a similar fashion (Fig. $3)$. The graft is wrapped in a saline-soaked sponge and placed into the chest cavity, taking care not to kink or twist the vascular pedicle. The diaphragm is then incised along its posterolateral chest wall insertion and the retroperitoneal space is entered. The segmental vessels are isolated and ligated with clips and the vertebral bodies prepared to accept the vascularised rib graft.

After anterior decompression a femoral head and neck allograft may be used to occupy the space left after vertebral body resection. A laminectomy spreader is placed between the two opposing vertebrae and, with the calcar facing anteriorly, the graft is wedged into position. A high-speed dental burr is then used to cut a slot in the lateral cortex of the allograft and also in the adjacent vertebral bodies above and below the decompression area. The vascularised rib graft is then trimmed to the appropriate length and the soft tissue on the side of the rib opposite the intercostal vessel is carefully elevated to one-third or one-half the rib width to allow direct bone contact when the graft is inserted. The rib is then impacted into the slot with the intercostal vessel on the lateral aspect of the slot: this prevents any compromise of rib vasculature. The diaphragm and chest are then closed in a routine fashion. An anterior implant, if used, may be inserted after decompression, distracted gently to allow for insertion of the graft and then compressed to improve fixation of the graft.

Postoperative management depends upon the indications and technique of operation. If the operation was to correct kyphosis, and if discectomies with interbody fusions were done at each level, then posterior instrumentation may be necessary as a second-stage procedure.

\section{RESULTS}

Results were analysed for 25 of the 27 patients in whom this procedure was performed: follow-up ranged from 24

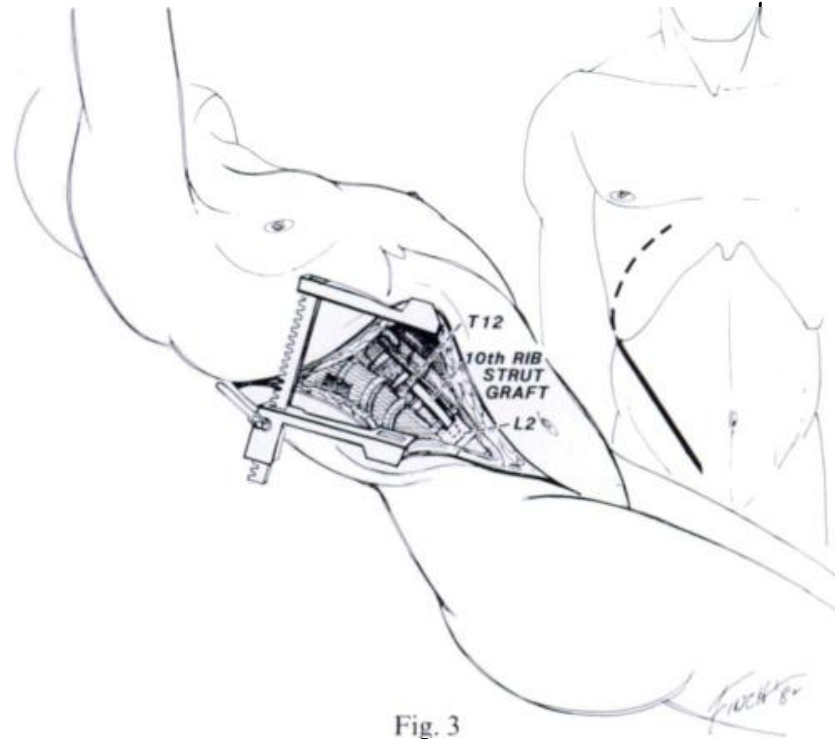

A thoraco-abdominal incision is made and the tenth rib graft placed between $T 12$ and L2 in a slot cut into the vertebral bodies.

to 62 months (average 34 months), the duration of postoperative immobilisation ranged from 5 to 24 weeks (average 11 weeks). Radiographic evidence of carly incorporation of the bone graft was seen in all patients at about eight-and-a-half weeks (range 4 to 16 weeks).

Pain. Before operation 14 patients had significant back pain associated with the kyphosis. When last seen at follow-up 12 had complete relief of pain; in one the pain. despite operation, remains the same and another still has minimal discomfort though his pain has been substantially relieved.

Correction of the kyphosis. The degree of correction has varied and seems related to the pre-operative condition (Figs 4 to 9). In one patient presenting with a myelomeningocele, a pre-operative thoracolumbar kyphosis of 135 was corrected to 36 and at follow-up 62 months later it was 41 ; this patient had undergone cord resection and vertebral body resection posteriorly with

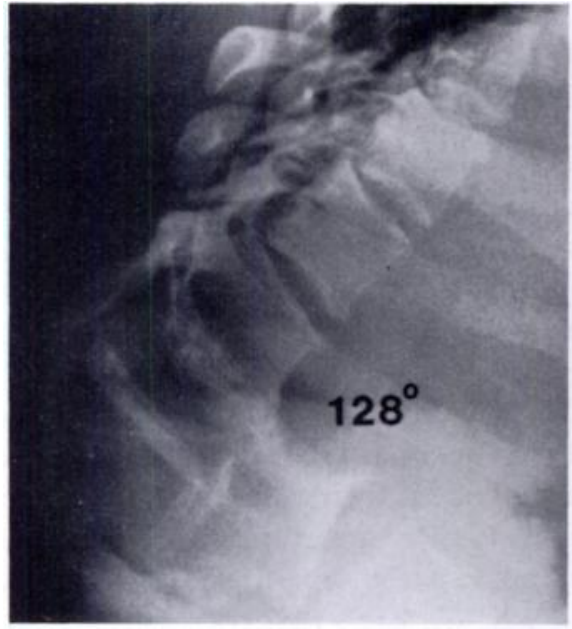

lig. 4

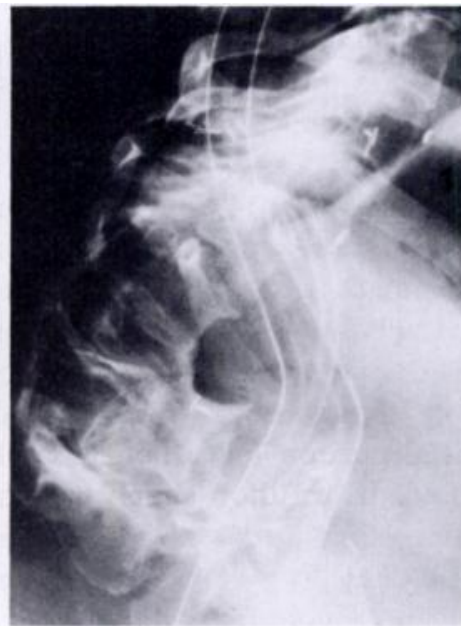

Fig. 5

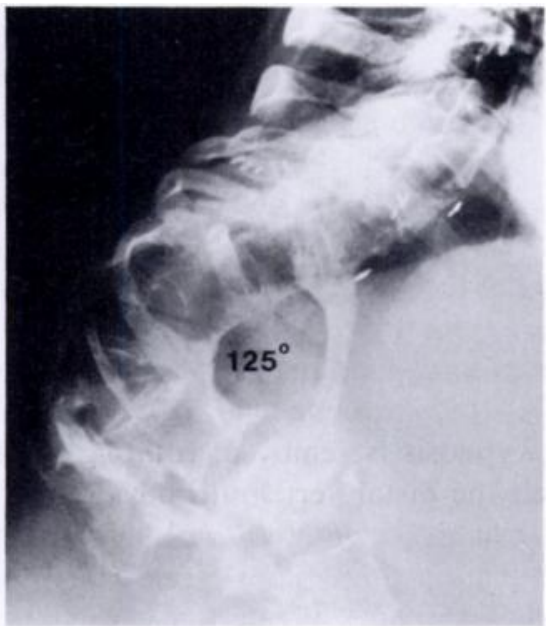

Fig. 6

Figure 4--An adult with a severe kyphosis of 128 associated with achondroplasia. Figure 5 - A vascularised rib graft has been inserted discectomy was not performed. Figure 6-Eighteen months after operation a lateral radiograph shows that the graft has hypertrophied: it remains intact and appears to be completely consolidated. 


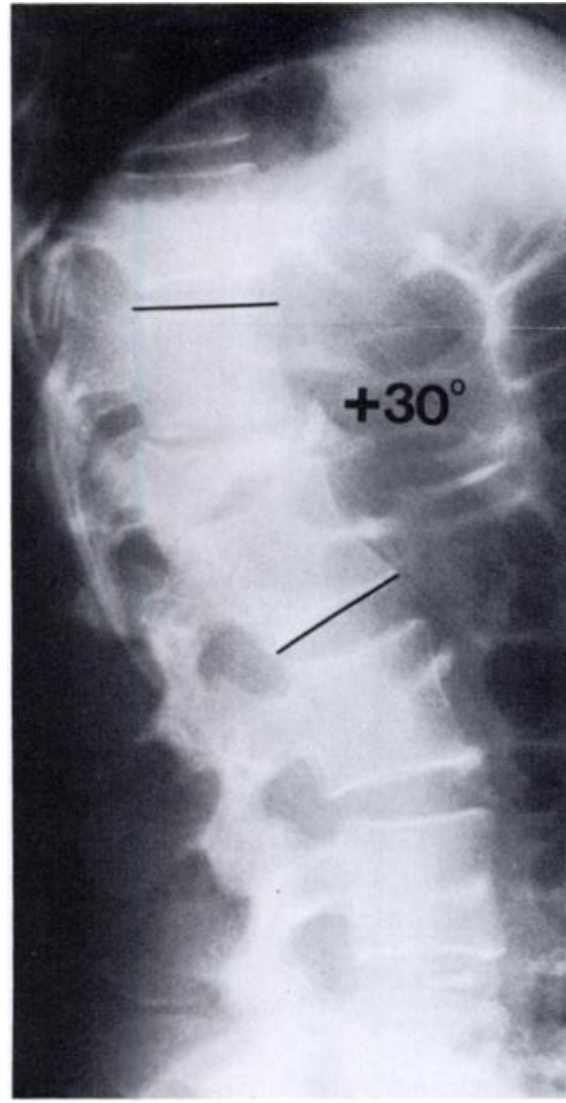

Fig. 7

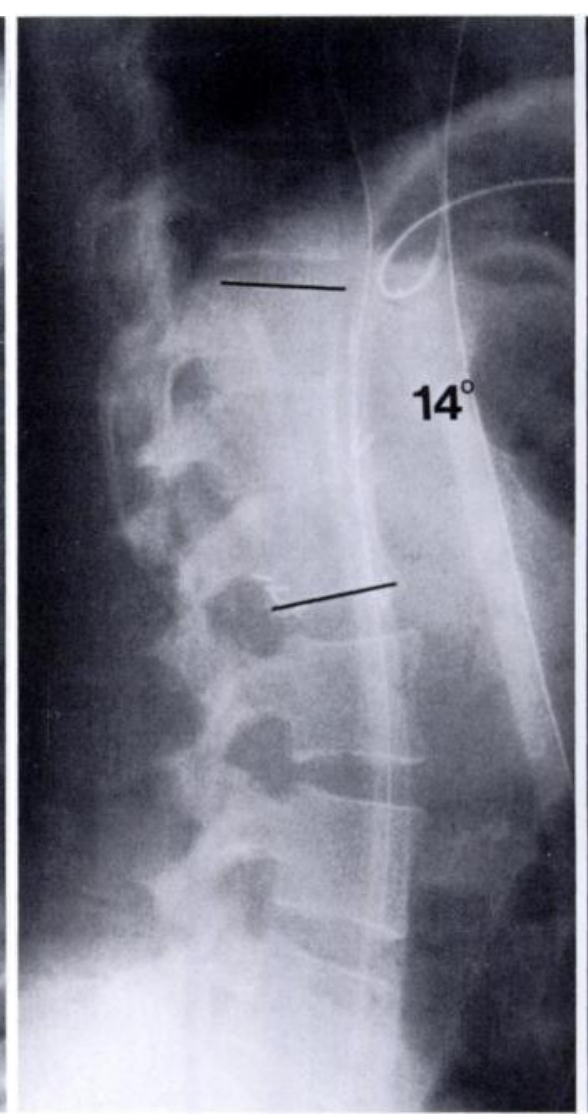

Fig. 8

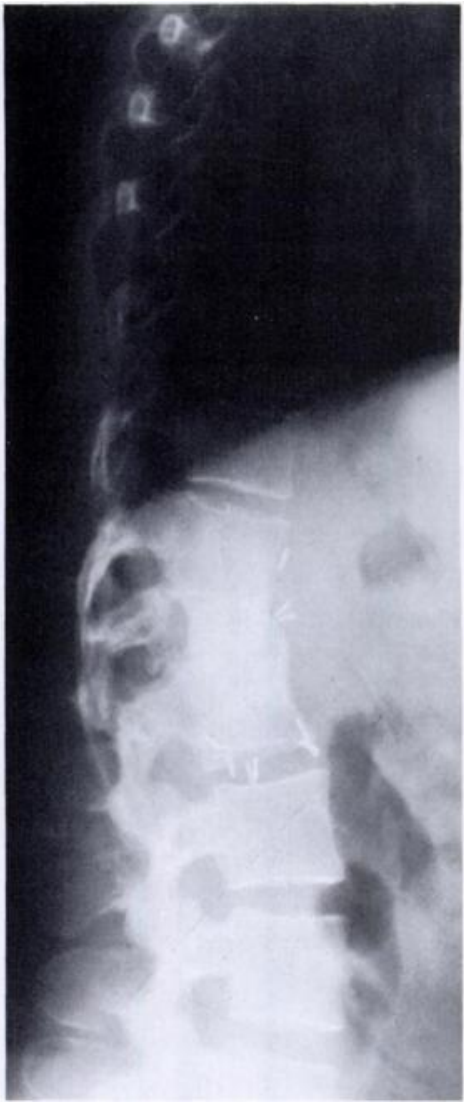

Fig. 9

Figure 7-The radiograph of a patient who presented with an incomplete paraparesis following an old burst fracture of Ll. Figure 8 After anterior cord decompression and anterior spinal fusion using a vascularised rib graft with a femoral head allograft, the kyphosis has been partially corrected and the spinal canal decompressed. Figure 9-At follow-up partial loss of correction with partial collapse of the femoral head allograft is noted. Fusion is, however, solid. The patient has recovered some neurological function and pain has been relieved.

Harrington instrumentation, followed by anterior vascularised rib grafting as a second-stage procedure. In the three patients with osteomyelitis, the average preoperative kyphosis was 39 : at follow-up (average 37 months) it was 40 . In the patient with post-laminectomy kyphosis, the deformity was 68 . while at follow-up 47 months later it was 42 with complete neurological recovery. In the remaining 20 patients with traumatic kyphosis, the pre-operative kyphosis averaged 36 (range from 7 to 90 ): at follow-up (average 34 months), it was 31 (range 7 to 85 ). Seven of the 25 patients (28\%) lost five degrees or more of correction postoperatively (range 6 to 19 , average 12 ).

Neurological deficit. Thirteen patients underwent spinal cord decompression: 12 had anterior decompression at the time of the anterior strut fusion and one had a posterolateral decompression with reduction of the fracturedislocation at the time of posterior spinal fusion. In 11 patients the indication for a cord decompression was incomplete neurological deficit and, in two, severe radicular pain. A modified Frankel classification system (Frankel et al. 1969) was used to classify the neurological deficit and the results at follow-up. The two patients with radicular pain had complete relief of their symptoms at final follow-up. The one patient with osteomyelitis initially classified as " $B$ " subsequently had return of neurological function and was classified as " $E$ ". Of the remaining 10 patients, four had complete recovery, five showed improvement in neurological function, and one became worse 20 months after operation: a follow-up CT scan and myelogram on this patient demonstrated that the anterior decompression was incomplete.

\section{COMPLICATIONS}

Complications after anterior spinal fusion occurred in six patients: atelectasis in two, transient ileus in one, superficial thoracotomy wound infection in one. a neuroma over the thoracotomy site in one, and loosening of the anterior implant with a loss of correction of 9 in one patient.

A seventh patient (Case 8) developed increasing spasticity in the lower extremities and a gradual loss of sensitivity to pinprick in the upper thoracic area (T2-T3) 20 months after anterior decompression and anterior spinal fusion. A metrizamide myelogram and a CT scan showed minimal compression of the spinal cord at the apex of the kyphosis; this patient underwent hemilaminectomy and posterolateral decompression of the spinal 
canal at T2 T3 and at the most recent follow-up had some improvement in the spasticity but no improvement in gait.

Seven patients had a loss of correction of more than 5 (range 6 to 19 : average 12.3 ): three of these patients also had a posterior spinal fusion with Harrington instrumentation. while one had insertion of an anterior implant at the time of the anterior procedure. All seven had no further complications and no subsequent loss of correction was seen at follow-up.

\section{DISCUSSION}

In the management of kyphosis the use of fibular grafts or rib strut grafts to provide anterior support and to promote eventual fusion is a useful technique (Bradford $e t$ al. 1977: Malcolm et al. 1981). In severe kyphosis, it has been found that placement of the bone graft anterior to the vertebral bodies over the apical segments affords the best results: it provides a distinct mechanical advantage by preventing further collapse of the deformity in the sagittal plane (White. Panjabi and Thomas 1977). However, we had previously found that bone grafts placed more than $4 \mathrm{~cm}$ anterior to the apical vertebral body are more likely to fracture during bone consolidation, revascularisation and healing (Bradford et al. 1982): this complication has also been reported by other authors (Yau et al. 1974: Streitz et al. 1977; Stagnara 1978; Gonon et al. 1981). Our technique of vascularised grafting would thus appear to be advantageous, particularly in those cases where the strut graft is anterior to the vertebral bodies. Of the 11 patients in this series where the anterior strut technique was used, three of the grafts lay $4 \mathrm{~cm}$ or more anterior to the apical vertebra and not one of these has fractured.

It was particularly interesting to note how rapidly bony consolidation and healing occurred: assessed radiographically. these grafts appeared to heal within 11 weeks of insertion. As has recently been reported, the blood flow gradient from a graft to a vertebral body is favourable for graft viability (Shaffer 1984). Hypertrophy of the graft. on the other hand, was difficult if not impossible to measure accurately, although it is our impression that this has indeed occurred in several cases.

The use of the technique described does not preclude more radical approaches for correction of kyphosis, although the procedure is uniquely suited for stabilisation in situ. In growing children a single-stage in situ stabilisation for kyphosis using this approach would be contra-indicated, since one may produce a progressive deformity by creating an anterior tether in the presence of continuing posterior growth. In children, therefore, if anterior vascularised strut grafting is contemplated, a second-stage posterior arthrodesis is advisable.

\section{REFERENCES}

Bradford DS, Winter RB, Lonstein JE, Moe JH. Techniques of anterior spinal surgery for the management of kyphosis. Clin Orthop 1977: 128: 12939.

Bradford DS. Anterior vascular pedicle bone grafting for the treatment of kyphosis. Spine 1980:5:318 23.

Bradford DS, Ganjavian S, Antonious D, Winter RB, Lonstein JE, Moe JH. Anterior strut-grafting for the treatment of kyphosis: review of experience with forty-eight patients. J Bone Joint Surg $[\mathrm{Am}]$ 1982:64 A:680-90.

Frankel HL, Hancock DO, Hyslop G, et al. The value of postural reduction in the initial management of closed injuries of the spine with paraplegia and tetraplegia. I. Paraplegia 1969;7:179-92.

Gonon GP, de Mauroy JC, Frankel P, Campo-Paysaa A, Stagnara P. Greffes antérieure: en ètai dans le traitement des cyphoses et cyphoscolioses. Rev Chir Orthop 1981:67:731 45 (Eng. Abstr.).

Hall JE, Poitras B. The management of kyphosis in patients with myelomeningocele. Clin Orthop 1977:128:3340.

Hodgson AR. Correction of fixed spinal curves; a preliminary communication. J Bone Joint Surg [Am] 1965:47 A:1221 7 .

Hodgson AR, Stock FE. Anterior spine fusion for the treatment of tuberculosis of the spine: the operative findings and results of treatment in the first one hundred cases. J Bome Joint Surg $[\mathrm{Am}]$ 1960:42 A:295 310.

Johnson JTH, Robinson RA. Anterior strut grafts for severe kyphosis: results of 3 cases with a preceding progressive paraplegia. Clin Orthop 1968:56:25-36.

Malcolm BW, Bradford DS, Winter RB, Chou SN. Post-traumatic kyphosis: a review of forty-eight surgically treated patients. $J$ Bonc' Joint Surg $[\mathrm{Am}]$ 1981:63 A:891 9.

McBride GG, Bradford DS. Vertebral body replacement with femoral neck allograft and vascularized rib strut graft: a technique for treating post-traumatic kyphosis with neurologic deficit. Spine 1983:8:406-15

Moe JH, Winter RB, Bradford DS, Lonstein JE. Scoliosis and other spinal deformities. Philadelphia etc: WB Saunders. 1978.

Rose GK, Owen R, Sanderson JM. Transposition of rib with blood supply for the stabilisation of a spinal kyphos. J Bome Joint Surg [Br] 1975:57 B:112.

Shaffer JW. Rib transposition vascularized bone grafts-hemodynamic assessment of donor rib graft and recipient vertebral body. Orthop Trans 1984;8: 153.

Stagnara P, de Mauroy J-C, Gonon G, Campo-Paysaa A. Scolioses cyphosantes de l'adulte et greffes antérieures. International orthopaedics (SICOT). Berlin etc: Springer-Verlag, 1978:14965.

Stener BSC. Resection of the spine for tumours. Orthopaedic surgery and traumatology: Proceedings of the 12th Congress of the International Society of Orthopaedic Surgery and Traumatology. Tel Aviv 1972. Amsterdam: Excerpta Medica 1973:384 6.

Streitz W, Brown JC, Bonnett CA. Anterior fibular strut grafting in the treatment of kyphosis. Clin Orthop 1977:128:140 8 .

Weiland AJ, Moore JR, Daniel RK. Vascularized bone autografts. Clin Orthop 1983:174:87 95.

White AA III, Panjabi MM, Thomas CL. The clinical biomechanics of kyphotic deformities. Clin Orthop 1977:128:8 17.

Yau ACMC, Hsu LCS, O'Brien JP, Hodgson AR. Tuberculous kyphosis: correction with spinal osteotomy, halo-pelvic distraction and anterior and posterior fusion. J Bome Joiml Surg $[\mathrm{Am}]$ 1974:56 A 141934. 